\title{
Movements, connectivity, and space use of immature green turtles within coastal habitats of the Culebra Archipelago, Puerto Rico: implications for conservation
}

\author{
Lucas P. Griffin ${ }^{1, *}$, John T. Finn ${ }^{2}$, Carlos Diez ${ }^{3}$, Andy J. Danylchuk ${ }^{1}$ \\ ${ }^{1}$ Department of Environmental Conservation and Intercampus Marine Science Graduate Program, \\ University of Massachusetts Amherst, 160 Holdsworth Way, Amherst, MA 01003, USA \\ ${ }^{2}$ Department of Environmental Conservation, University of Massachusetts Amherst, 160 Holdsworth Way, Amherst, \\ MA 01003, USA \\ ${ }^{3}$ Programa de Especies Protegidas, DRNA-PR, San Juan, PR 00936, Puerto Rico
}

\begin{abstract}
Juvenile green turtles occupy coastal marine habitats important for their ontogeny; however, the details of their movement, connectivity, and space use in these developmental habitats are still poorly understood. Given that these areas are often threatened by human disturbance, additional information on green turtle spatial ecology is needed to meet conservation endpoints for this endangered species. For this study, we used fixed passive acoustic telemetry to (1) describe movement patterns and connectivity of immature green turtles within, outside, and across 2 bays, Manglar and Tortuga bays, on Culebra and Culebrita islands, Puerto Rico; and (2) determine spatio-temporal drivers of the presence and absence of turtles within Manglar Bay. Network analysis used to quantify movement patterns showed that turtles in our study exhibited differential space use with little to no connectivity across the 2 bays. In addition, turtles exhibited high site fidelity, with larger turtles leaving on brief trips. We applied a presence-absence Bayesian binomial model on a subset of 9 turtles at an hourly temporal scale and showed that turtles within Manglar Bay occupied areas of lagoon and seagrass habitats at night and were rarely using areas of macroalgae habitat. The parameter estimates from the model enabled us to predict the space use of turtles across Manglar Bay, and the hourly probability distributions highlighted predictive diel movement patterns across the bay. Considering the importance of juvenile and subadult life stages for population viability, we recommend continued protection of these critical juvenile turtle developmental habitats to ensure recruitment into the adult life stage.
\end{abstract}

KEY WORDS: Acoustic telemetry $\cdot$ Bayesian statistics $\cdot$ Chelonia mydas $\cdot$ Connectivity $\cdot$ Integrated nested Laplace approximation $\cdot$ INLA $\cdot$ Network analysis

\section{INTRODUCTION}

The globally threatened green turtle Chelonia mydas relies on shallow neritic foraging grounds for up to multiple decades until reaching or nearing sexual maturity (Bjorndal et al. 2000, Bolten 2003, Parker et al. 2011). Here, within these developmental areas, turtles will switch from their omnivorous oceanic foraging strategy to foraging largely on herbivorous

\footnotetext{
*Corresponding author: lucaspgriffin@gmail.com
}

seagrass and algae (Bjorndal 1997, Heppell et al. 2002, Bolten 2003, Jones \& Seminoff 2013). They are believed to occupy relatively small and specific home ranges, but range size can vary due to habitat complexity (Mendonca 1983, Ogden et al. 1983, Brill et al. 1995, Whiting \& Miller 1998, Seminoff et al. 2003, Makowski et al. 2006, Taquet et al. 2006, Hazel et al. 2009, Blumenthal et al. 2010, Lamont et al. 2015). For example, the home range of immature green turtles

() The authors 2019. Open Access under Creative Commons by Attribution Licence. Use, distribution and reproduction are unrestricted. Authors and original publication must be credited.

Publisher: Inter-Research · www.int-res.com 
(50.9-82.5 cm straight carapace length, SCL) was $>16 \mathrm{~km}^{2}$ in the Gulf of California, where food resources are widely dispersed (Seminoff et al. 2002). Conversely, Brill et al. (1995) noted an average home range of $<3 \mathrm{~km}^{2}$ for immature green turtles $(<65 \mathrm{~cm}$ carapace length) in Kaneohe Bay, Hawaii, where both food resources and shelter were tightly clustered together. Makowski et al. (2006) reported 3 $\mathrm{km}^{2}$ average home ranges for immature green turtles (27.9-48.1 cm SCL) in Florida, with high-use areas ranging between 0.18 and $1.17 \mathrm{~km}^{2}$. Further, the sizes of immature turtles may affect their home range sizes, with larger immature turtles using deeper open waters and smaller immature turtles using shallow protected bays (Seminoff et al. 2003, Koch et al. 2007, Bresette et al. 2010). Overall, these studies suggest that immature green turtles inhabit well-defined habitats with high variability between home range sizes due to ecological differences in food and shelter resource availabilities and differences in body size (Makowski et al. 2006, Lamont et al. 2015).

Considering their complex life history, anthropogenic stressors may impact sea turtle populations disproportionately across life stages (Hamann et al. 2010, Wallace et al. 2010). Sea turtles exhibit high levels of hatchling mortality and late age at sexual maturity; thus, high survival rates are critical for larger juveniles and adults if populations are to persist (Congdon \& Dunham 1997). While natural sea turtle mortality decreases with body size, there is an elevated consequence for a population when larger individuals are removed just prior to reaching maturity (Heppell et al. 2002). Within a stable stage distribution population (i.e. proportion of individuals remained constant across both age class and time), large immature sea turtles will account for the majority of the population, making their survivorship critical for population growth or decline (Heppell 1998, Heppell et al. 2000). Consequently, protecting developmental habitats and helping ensure recruitment of immature turtles to sexual maturity is essential for maintaining population viability.

In Puerto Rico, the Culebra Archipelago provides important developmental feeding habitats for immature green turtles (Collazo et al. 1992). Recognizing the area's importance, the US National Marine Fisheries Service designated Culebra as Resource Category I critical habitat for the green turtle in 1998 (Federal Register; 63 FR 46693, September 2, 1998), and federal management and conservation measures are required within all coastal habitats within $3 \mathrm{~nm}$ $(5.6 \mathrm{~km})$ from Culebra. Green turtles have been most intensively studied in 2 bays around Culebra, on the easternmost side of Culebra in Manglar Bay and the on the small island of Culebrita (east of Culebra) in Tortuga Bay (Collazo et al. 1992, Velez-Zuazo et al. 2010, Patrício et al. 2011, 2014, 2016, 2017). Although these 2 bays are in close proximity, there are relatively few records of green turtles moving between the bays based on a mark-recapture study with sampling occurring approximately twice during a given year (Patrício et al. 2011). Immature green turtles spend decades in these nearshore developmental habitats. Because these habitats are increasingly affected by anthropogenic disturbances, more information is needed on turtle movements, connectivity, and space use within them. Considering that the habitat composition and structure in these 2 bays are different, understanding turtle movement and connectivity in relation to the bays may provide additional insights on immature green turtle ecology. The purpose of this study was to (1) evaluate movement patterns and connectivity of immature green turtles within, outside, and across 2 bays, Manglar Bay on Culebra Island and Tortuga Bay on Culebrita Island, Puerto Rico; and (2) assess spatio-temporal drivers of the presence and absence of turtles within Manglar Bay.

\section{MATERIALS AND METHODS}

\subsection{Turtle tagging study sites}

The 2 study sites where turtles were tagged, Manglar Bay, Culebra Island (Fig. 1), and Tortuga Bay, Culebrita Island, are $30 \mathrm{~km}$ east from the main island of Puerto Rico. Both sites are shallow, ranging from 1 to $15 \mathrm{~m}$ deep, but the 2 bays differ in structure and habitat types (Fig. 1). Manglar Bay has deep lagoons $(5-15 \mathrm{~m})$ surrounded by mangroves on the perimeter, shallow seagrass and macroalgal flats $(0.5-2 \mathrm{~m})$ intermixed, and a linear reef outside the bay. Tortuga Bay has a more uniform depth across a deep basin with a shallow sandy perimeter. The bay consists primarily of colonized hard bottom, sand with scattered seagrass, and coral (Diez et al. 2010). A $2 \mathrm{~km}$ wide and $20 \mathrm{~m}$ deep channel, Culebrita Strait, separates these 2 areas.

\subsection{Turtle capture and tagging}

Turtles were captured following procedures used by Diez et al. (2010) in collaboration with the sea turtle surveys conducted annually by the Departamento 


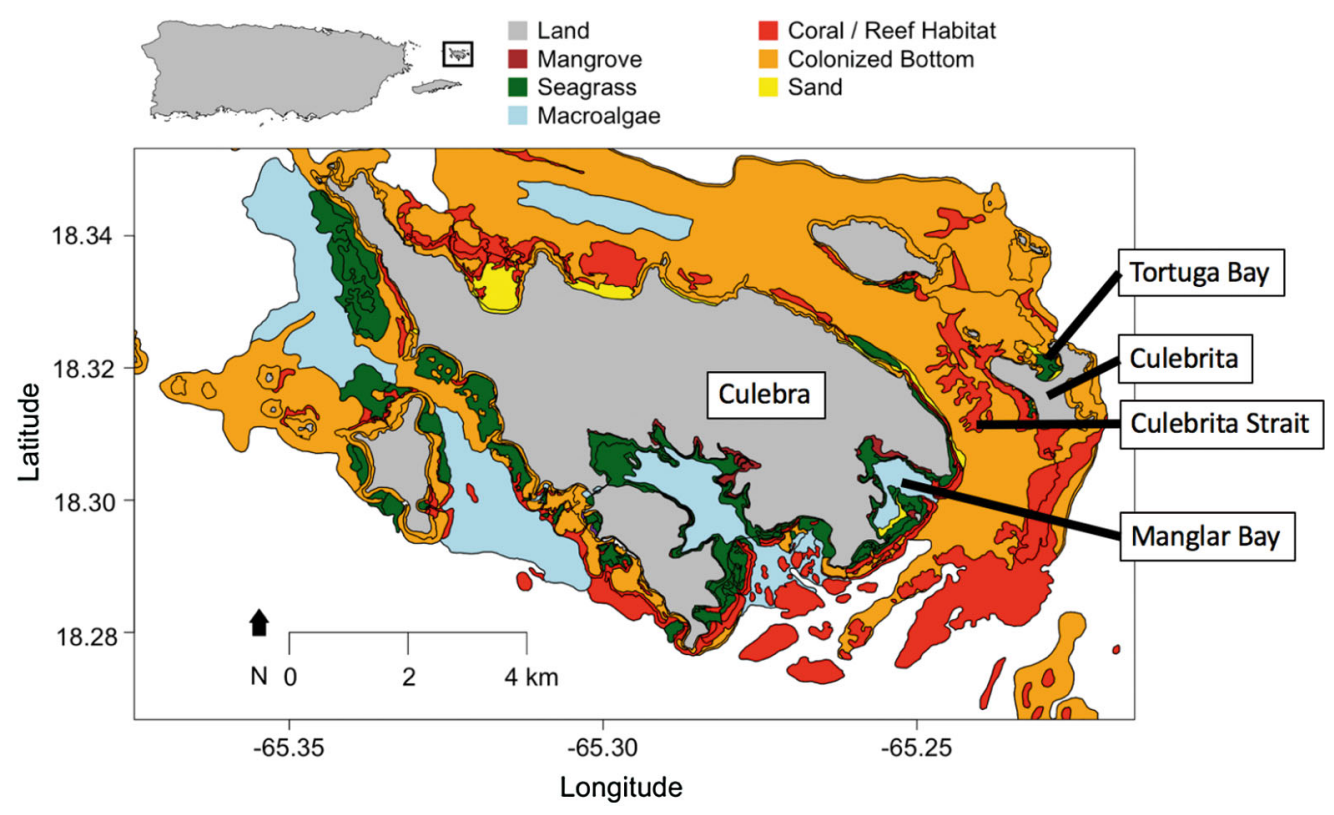

Fig. 1. Study sites around Culebra and Culebrita, Puerto Rico, including Manglar Bay, Tortuga Bay, and Culebrita Strait, Puerto Rico. In addition, habitats of interest are displayed (https://products.coastalscience.noaa.gov/collections/benthic/ e95usvi_pr/)

de Recursos Naturales y Ambientales de Puerto Rico and US Fish and Wildlife Service. Turtles were captured using a $200 \times 5 \mathrm{~m}$ seine net (no. 18 nylon twine, $25 \mathrm{~cm}$ stretch mesh) deployed in shallow water areas no deeper than $5 \mathrm{~m}$. With the net deployed, a boat carefully cruised the inner turtle foraging area of the bay, producing a disturbance that caused turtles to move towards the net. In smaller, shallower areas, swimmers snorkeled inside the capture area and chased turtles towards the net. A minimum of 6 swimmers snorkeled along the net, retrieving all entangled turtles. Each turtle was brought aboard the boat to measure mass and SCL (using Haglof 65 and $95 \mathrm{~cm}$ tree calipers) and have both front flippers tagged with 2 external tags (Inconel and/or plastic tag). Digital pictures of the carapace and plastron were taken for each individual turtle and any abnormalities, such as fibropapillomatosis tumors, noted.

Turtles were tagged with coded ultrasonic transmitters (Vemco V16-1L transmitters, $16 \mathrm{~mm}$ diameter, $54 \mathrm{~mm}$ length; $8.1 \mathrm{~g}$ in water; $60-180 \mathrm{~s}$ ping interval; 10 yr battery life) between March 2013 and March 2014. Transmitters were attached to right side caudal marginal scutes on the dorsal surface. To prepare the location, coarse sand paper (400 grit) was used to remove epibionts from the carapace surface; the carapace was then wiped with isopropyl alcohol $(70 \%)$ and dried, and acrylic paint was applied. The transmitter was attached to the carapace by drilling 2 holes $(8 \mathrm{~mm})$ into the marginal scutes and then secured with a stainless steel wire cable (cable strength $27 \mathrm{~kg}$ ) and embedded into a base of West Marine epoxy, with the marine epoxy applied on top of the transmitter to cover and streamline it. Positioning was designed to minimize the risk of tag damage or loss by collisions with coral and to reduce hydrodynamic interference. Additionally, positioning ensured that the transmitter was submerged at all times, even when turtles surfaced.

\subsection{Fixed passive receiver array}

Movement patterns of tagged green turtles were monitored using a fixed passive acoustic receiver array (VR2W-69kHz receivers, Vemco) comprised of 59 receivers. Individual receivers were secured to rebar $(1 \mathrm{~m})$ and anchored into a concrete block $(23 \mathrm{~kg})$. Receivers were strategically placed within bays, on the perimeter of bays, and around Culebra Island to maximize the detections of animal movements. The fixed passive receiver array was originally developed to monitor the movements of multiple species (Finn et al. 2014, Brownscombe et al. 2019); thus, receivers were placed in a wide range of habitats including shallow reef flats $(<3 \mathrm{~m})$, enclosed embayments $(<15 \mathrm{~m})$, and open water reef systems $(<45 \mathrm{~m})$ (Figs. $1 \& 2)$. Depths for receivers ranged from approximately 1 to $20 \mathrm{~m}$. Receivers were deployed as follows: 7 in Manglar Bay, 25 as a Vemco 


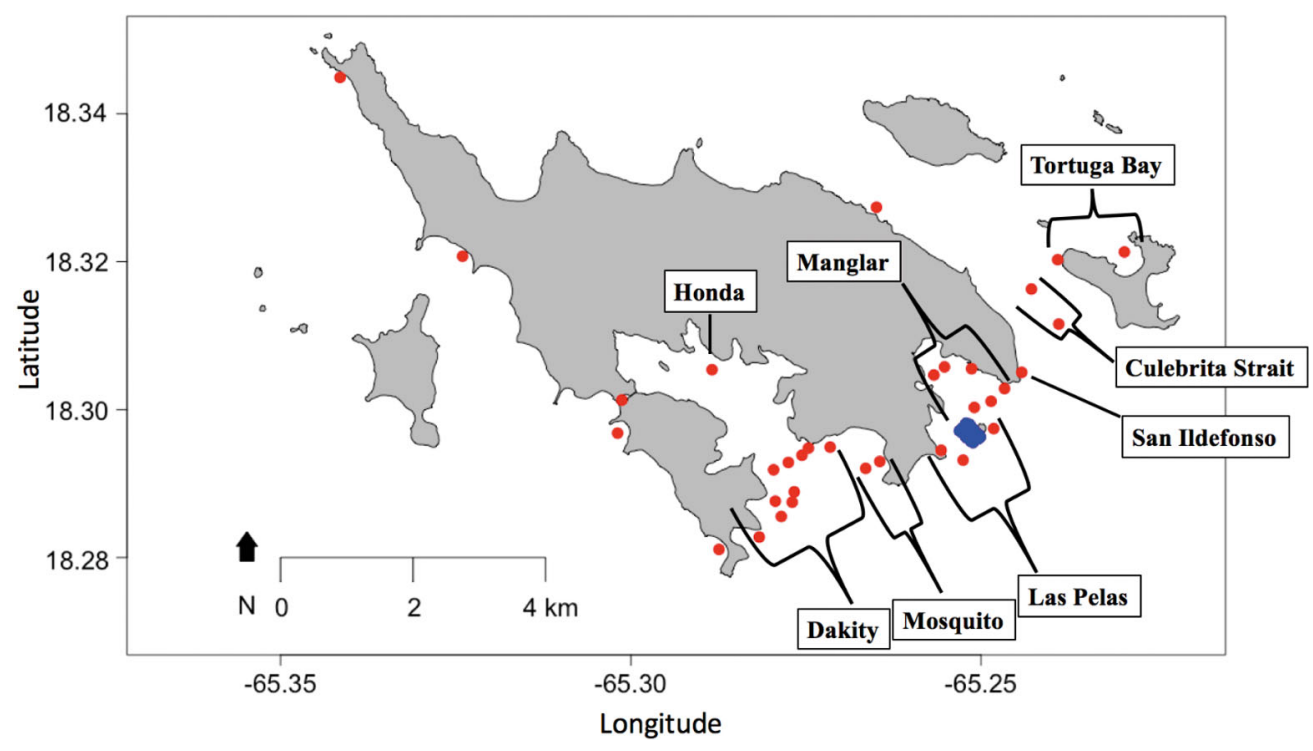

Fig. 2. Manglar and Tortuga Bays of Culebra, Puerto Rico, with 59 receivers (red and blue dots) deployed around Culebra Island. Twenty-five receivers (blue dots) were positioned as a Vemco positioning system (VPS) on the perimeter of Manglar Bay; based on the general VPS location of the receivers, they were categorized as either VPS Lagoon $(n=17)$ or VPS Reef $(n=8)$ receivers. The remaining 34 receivers around the islands are labeled with red dots. Corresponding receiver classified regions (i.e. Honda, Dakity, Mosquito, Las Pelas, Manglar, San Ildefonso, Culebrita Strait, and Tortuga Bay) used for the bipartite graphs are labeled

positioning system (VPS) on the perimeter of Manglar Bay, 2 in Tortuga Bay, 2 in the channel between Manglar Bay and Tortuga Bay (Culebrita Strait), and 23 around Culebra Island's perimeter (Fig. 2).

The VPS, a fine-scale positioning system that enables the trilateration of detection data into positioning estimates, was designed for a shallow water marine fish (see Brownscombe et al. 2019) and did not generate ecologically relevant positioning data for green turtles in this study. However, as we employed anchored sync tags within the VPS, originally deployed to assist fine-scale positioning estimates of detections, we were able to use the sync tag detections to generate multiple linear regressions (zero inflated binomial) and thus understand detection probabilities across distance. Although dependent on environmental conditions (e.g. wind, temperature, diel phase), our regressions, based on optimal environmental conditions, indicated our receivers roughly had a detection radius of $80 \mathrm{~m}$ at $50 \%$ detection efficiency. Detection probabilities were calculated for receivers (approximately 1-8 $\mathrm{m}$ depth) within the shallow VPS only and, thus, were likely higher in deeper water.

\subsection{Data processing and analyses}

Detection data were exported from a VUE database (Vemco) and analyzed in the R statistical envi- ronment (R Development Core Team 2018). Data were corrected for receiver clock drift, false detections created by simultaneous detection collisions, and ricochet (multipath) detections or echoes created by complex bathymetry (Kessel et al. 2015). The first $7 \mathrm{~d}$ of each transmitter detection log were removed to avoid potential tagging effects. Each detection log was examined with abacus plots, showing detections at each station across time, to determine if the transmitter fell off within the array, which would result in many false detections for long periods of time. False detections within a detection log were identified when there were many consecutive detections on an individual receiver or on multiple closely placed receivers (if detection coverages overlapped). Detection logs were conservatively filtered accordingly to account for this potential issue.

\subsubsection{Network analysis}

Based in graph theory, network analysis is a valuable technique to examine acoustic telemetry movement data and to explore underlying ecological processes (Jacoby et al. 2012, Jacoby \& Freeman 2016). For each of the deployed transmitters and their respective spatial network, we calculated detection number, days at liberty (defined here as the period between date of release and date of the last detec- 
tion, excluding the first $7 \mathrm{~d}$ ), residency index, station count, and number of paths. Data are reported as mean \pm SD throughout, unless stated otherwise. Residency index was calculated by dividing the number of days detected by days at liberty within the study area (Reubens et al. 2013). As a VPS generates high levels of simultaneous detections, due to its design to trilaterate approximate true positions, we decided to aggregate detections from the 25 VPS receivers based on general location (i.e. either associated with lagoon or reef type habitats) into either VPS Lagoon ( $\mathrm{n}=17$ ) or VPS Reef $(\mathrm{n}=8)$ receivers. Specifically, station number was the number of stations an individual was detected on (i.e. receivers, including the VPS as VPS Lagoon and VPS Reef receiver aggregates), and a single path was defined as any unique node to node (station to station) movement. In addition, we calculated 3 network attributes: network density, average path length (APL), and mean betweenness $\left(\mathrm{Bi}^{\text {mean }}\right)$. The package igraph (Csardi \& Nepusz 2006) was used to generate network metrics and network graphs. Network density refers to the degree of available routes in a network, ranging from 0 to 1 ; a higher density value indicates multiple routes were used and available for a given individual (Lédée 2015, Lédée et al. 2015). APL is the average shortest number of steps for all used paths between nodes (i.e. stations); this measure indicates on average how easily individuals may move through the network (Kurvers et al. 2014). Bi indicates a node's importance via its connection strength to other nodes, based on the number of paths that pass through a specific node (the focal station) when taking the shortest path length from one node to another (Jacoby et al. 2012). We used an ANCOVA to test if detection number, days at liberty, residency index, station count, and number of paths differed between size (SCL) and capture location (Manglar Bay and Tortuga Bay). In addition, we used linear models to test for an effect between size and network density, APL, and $\mathrm{Bi}^{\text {mean }}$ for Manglar Bay individuals only, as Tortuga Bay did not have sufficiently extensive receiver coverage to calculate meaningful values.

\subsubsection{Movements, connectivity, and space use outside, within, and across bays}

Network analysis was further used to examine the movements, connectivity, and variation in space use across the study area. To examine these attributes across the study area and beyond just Manglar and Tortuga Bay, we used bipartite graphs (Dale \&
Fortin 2010). Here, these graphs are comprised of 2 different types of nodes, individuals and locations. Essentially, these bipartite graphs link individual turtles to the regions they visited. An important distinction is that these graphs are not spatially explicit but rather are a matrix that highlights the relationships (i.e. visits) between the individuals and locations. They are particularly useful when attempting to examine the variation in space use patterns across individuals or groups of individuals (Urban \& Keitt 2001, Fortuna et al. 2009, Jacoby et al. 2012, Finn et al. 2014, Heupel et al. 2019). The links between the individuals and locations, also referred to as the edges, are weighted by the number of detections at the given region. We aggregated the 26 stations (including the aggregated VPS receivers, see Section 2.4.1) into 8 areas that correspond to the area's geography: Honda, Dakity, Mosquito, Las Pelas, Manglar, San Ildefonso, Culebrita Strait, and Tortuga Bay (Fig. 2). By aggregating receivers into regions, we have also minimized issues surrounding detection efficiency (i.e. we have a high likelihood of detecting a passing individual within a region). To better observe space use patterns across the study area, the bipartite graphs were then plotted using the FruchtermanReingold force-directed layout algorithm (Fruchterman \& Reingold 1991). This algorithm generates attractive and repulsive forces among all the regions or nodes which are proportional to the weight of the edges connecting adjacent nodes (Tamassia 2013). Thus, if there was little or no attraction, then nodes would arrange in an equidistant circle (Finn et al. 2014). However, when strong attractions and connections exist between nodes, the nodes and their heavily weighted edges would be tightly connected to one another and, thus, form possible network communities. Ultimately, the FruchtermanReingold force-directed layout algorithm helps to visually decipher heterogeneous or homogeneous space use by animals.

\subsubsection{Community network structuring}

Potential network communities were identified across the 8 receiver regions using 6 community detection algorithms. These algorithms cluster nodes (i.e. individuals and locations) into modules (groups of individuals and locations, i.e. potential communities) and are useful to examine the core space use and the connectivity of different groups of individuals across the study area (Finn et al. 2014, Jacoby \& 
Freeman 2016). The clustering of nodes within modules is based on the strength of the connections to one another. When groups of nodes have tight connections to one another (e.g. high number of visits between each other), they are referred to as communities. The applied algorithms to cluster nodes into modules and thus identify potential communities were Leading-Eigenvector (Newman 2006), WalkTrap (Pons \& Latapy 2006), Fast-Greedy (Newman \& Girvan 2004), Spin-Glass (Reichardt \& Bornholdt 2006), Label-Propagation (Raghavan et al. 2007), and Multilevel (Blondel et al. 2008). Subsequently, modularity scores, used to assess the quality of potential network communities, were calculated for each community detection algorithm (Newman \& Girvan 2004). These scores are the fraction of edges within selected modules (i.e. community) minus the fraction that would occur if the edges were randomly distributed across nodes (Finn et al. 2014). Thus, modularity scores range from 0 to 1 , and the higher the modularity score for a community detection algorithm, the higher the quality of module divisions.

Each potential network community detected by an algorithm was assessed for significance by calculating the in-degree $\left(k_{i}^{\text {in }}\right)$ (number of links to nodes of the same module) and the out-degree $\left(k_{i}^{\text {out }}\right.$ (number of links to nodes outside its module) for each node within the given module. We used a Wilcoxon ranksum test to see if nodes, within a given module, were more linked to one another than with other individual modules or the entire network (Song \& Singh 2013). If a module is non-significant, $k_{i}^{\text {in }}$ and $k_{i}^{\text {out }}$ are about the same. If a module is significant, and it has significantly more nodes linked within it than to nodes in other modules (high $k_{i}^{\text {in }}$ ), it is labeled as a statistically significant community. If a module is significant and the nodes link more with nodes in other modules (high $k_{i}^{\text {out }}$ ), then it is labeled as an anti-community. Moving nodes from an anti-community module to another community would reduce modularity for the entire graph (Finn et al. 2014). Anti-communities are often corridors with many connections to other modules.

\subsection{Spatio-temporal drivers within Manglar Bay}

\subsubsection{Data structuring}

To examine turtle presence-absence distributions in Manglar Bay, we first created 8 new receiver aggregates or regions that specifically corresponded to the physical attributes of Manglar Bay and to nearby areas where turtles were regularly detected. Turtle presence or absence was binned by hour for each region. By aggregating receivers into regions and binning by hour, it is more likely we are capturing true presences and absences in Manglar Bay despite not formally incorporating detection efficiency. In addition, acoustic telemetry is a presenceonly type of data, with the term absence referring to the lack of detection since it is impossible to definitively determine if a tagged animal is truly absent in this system. Here, binning the data provided the best estimation of true absences.

\subsubsection{Model covariates}

Eight covariates were identified as potential predictors of green turtle presence and absence in Manglar Bay. These variables included 4 habitat variables (reef, lagoon, macroalgae, and seagrass), diel cycles (levels specified as day vs. night), tide states (levels specified as low, incoming, high, outgoing), tide height $(\mathrm{m})$, and tide daily range $(\mathrm{m})$. All continuous variables were standardized to have a mean of 0 and an SD of 1.

Using habitat data collected from NOAA (https:// products.coastalscience.noaa.gov/collections/benthic/ e95usvi_pr/), we generated relative habitat kernel density estimates (KDEs) (Sheather \& Jones 1991) around Culebra Island for each type of habitat: reef, lagoon, macroalgae, and seagrass. Other habitats (e.g. linear reef, forereef, unconsolidated bottom, and sand) were assessed but were eliminated due to high collinearity and variance inflation factor scores (i.e. these habitat types were highly correlated with one or more of the other habitat types) (Zuur et al. 2009). $\mathrm{KDE}$ bandwidth sizes were generated for each unique habitat in the study area (ranging from 100 to $1500 \mathrm{~m}$ ), and bandwidths incorporate both density and proximity of the focal habitat in the area. Using the habitat KDE bandwidth combinations, we derived all possible KDE point values for the derived 8 Manglar Bay regions and assessed the best bandwidth for each habitat using a series of random forest models (randomForest package, Liaw \& Wiener 2002) with turtle presences binned at the hourly level as the response variable.

Diel cycle was included at 2 levels, day vs. night, with periods of day and night assigned using the maptools package (Bivand \& Lewin-Koh 2013). Tide states, height, and daily range were derived from NOAA (https://tidesandcurrents.noaa.gov/ noaatidepredictions.html). 


\subsubsection{Statistical models and validation}

We modeled the hourly presence and absence of 9 turtles within each region of Manglar Bay across $60 \mathrm{~d}$ between December 2013 and February 2014, as a function of 8 covariates and with 4 dependency structures (i.e. spatial and temporal) in a binomial regression with a trial size of 9 . Only turtles with $<50 \%$ absences at the hour level were used. The response variable, hourly presence, for each region ranged from 0 to 9 . Selected habitat predictor variables for the full model, informed via random forest models, included reef at $500 \mathrm{~m}$ bandwidth, lagoon at $300 \mathrm{~m}$ bandwidth, macroalgae at $100 \mathrm{~m}$ bandwidth, and seagrass at $200 \mathrm{~m}$ bandwidth. Fixed covariates were reef (continuous), lagoon (continuous), macroalgae (continuous), seagrass (continuous), diel period (categorical with 2 levels), tide states (categorical with 4 levels), tide height (continuous), and tide daily range (continuous). The interaction terms were diel period (categorical with 2 levels) $\times$ seagrass, diel period $\times$ macroalgae, diel period $\times$ tide height, and tide height $x$ tide daily range. Habitat covariates were selected based on the habitats available to turtles within Manglar Bay. Diel period was a covariate of interest to determine if space use changed across day and night periods. Covariates involving tidal cycles (states, height, and range) were examined since they may affect the availability of habitats or may provide a mechanism of transport for foraging green turtles (Brooks et al. 2009).

A Bayesian analysis framework with integrated nested Laplace approximation (INLA) methodology (Rue et al. 2009) and binomial distribution was adopted to fit the data. INLA, which is able to handle large datasets, obtains the distribution of each parameter in a model while allowing for the incorporation of spatial and temporal dependency structures (i.e. autocorrelation) (Blangiardo \& Cameletti 2015, Zuur et al. 2017). Autocorrelation, inherent to tracking data, presents a difficult and confounding caveat of estimating space use of tagged animals (Johnson et al. 2013, Fleming et al. 2015, Winton et al. 2018). When autocorrelation is ignored, the assumption that observations are independent is violated and has the potential to produce biased parameter estimates (Zuur et al. 2017). INLA now enables researchers to include dependency structures to deal with autocorrelation while reducing computational times (Bakka et al. 2018). For example, because it outperforms more conventional methods that lack formal incorporation of autocorrelation structures, INLA was used by Winton et al. (2018) to estimate the distribution and relative density of loggerhead sea turtles along the North Atlantic coast.

Here, to fit the model, INLA was applied using the R-INLA package (Rue et al. 2009). To incorporate a spatial dependency structure (i.e. account for autocorrelation) into the model as a random effect, we utilized a mesh and the stochastic partial differential equation (SPDE) approach (see Lindgren et al. 2011, Zuur et al. 2017). Essentially, the mesh, comprised of non-overlapping triangles (i.e. lines and vertices), provides a means to effectively approximate the spatial field across our study site, which helps to reduce issues with autocorrelation (see Zuur et al. 2017). This spatial random effect was assumed to have a zero mean prior Gaussian distribution with a Matérn covariance structure (Muñoz et al. 2013). Since approximation of the SPDE approach improves with finer meshes (i.e. more vertices) but increases computation, we generated multiple mesh sizes and ultimately selected a mesh with 2155 vertices (Fig. 3). Finally, we used 3 dependency structures as random walk smoothers to help account for temporal autocorrelation issues, including tide height, hour of the day, and study day.

Random walk smoothers change in shape depending on the penalized complexity (PC) prior selection (Zuur et al. 2017). We ran the full candidate model with 27 possible PC prior combinations to examine the effect and to select the best combination of informed PC priors for these trends. The best combination of PC priors was determined via the widely applicable information criterion (WAIC) (Watanabe 2010). A lower WAIC value indicates an improved model by assessing the quality of fit vs. model complexity (Watanabe 2010).

We performed backward stepwise model selection to choose the best combination of variables from the full candidate model, again using WAIC and the selected random walk informative PC priors. A posterior distribution was obtained for each included parameter, enabling probability statements about each focal parameter. Unlike frequentist analyses where CIs and means are produced, the 0.025 and 0.975 quantiles of each posterior distribution (the credible interval) indicate the unknown parameter is $95 \%$ likely to fall within that range of values.

The final model was examined for homogeneity by plotting the residuals against fitted values and for potential patterns in residuals by plotting residuals vs. each covariate in the model and each covariate not in the model. We plotted residuals vs. spatial and temporal dependency structures (i.e. variograms and autocorrelation function plots) to assess existing issues with 


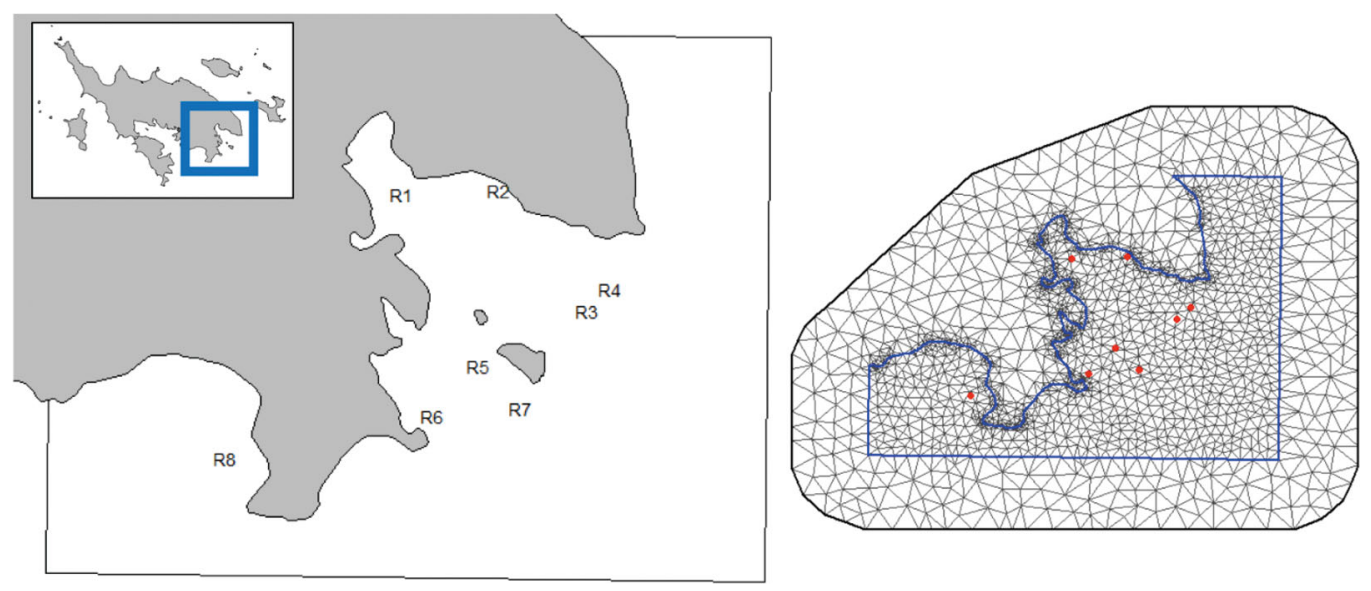

Fig. 3. Left panel: Manglar Bay area with 8 receiver aggregates or regions specified (R1-R8). Right panel: generated mesh, comprised of non-overlapping triangles, used to approximate the spatial random field. Finer meshes leading to better approximations but longer computational times help to reduce issues associated with autocorrelation. Our mesh contained 2155 vertices which were used to account for spatial dependency within the presence-absence binomial model of 9 turtles within Manglar Bay. Red dots represent the 8 receiver aggregates or regions

autocorrelation. To evaluate model performance and predictive accuracy, we generated a confusion matrix (i.e. a classification table that compares actual and predicted presences and absences to one another), calculated a dispersion statistic, compared the predicted and observed values using the full dataset, and, in addition, simulated from the posterior distributions of the regression parameters a thousand times to further assess under- or overdispersion (see Zuur et al. 2017).

\subsubsection{Spatio-temporal predictions}

Using the final model, we predicted the spatiotemporal distribution of turtles within and around Manglar Bay by hourly level. We derived 2155 habitat point estimates from our original mesh's vertices (2155 vertices) and from each habitat $\mathrm{KDE}_{\text {; }}$ this mesh was originally generated via the SPDE approach. These point estimates were used to help predict turtle distribution across Manglar Bay at each hour. Further, we made spatially explicit delineations for each station region, used the mean tide height and tidal range and median study day (296), and used the classification of day or night depending on the hour within the predictive model.

\section{RESULTS}

Movement data were examined from 21 turtles captured from Manglar Bay via 26 transmitters; 5 turtles were re-captured and re-tagged with acoustic trans- mitters due to tag loss (March 2013, $\mathrm{n}=8$; December 2013, $\mathrm{n}=14 ;$ March 2014, $\mathrm{n}=4$ ). From Tortuga Bay, 10 turtles were captured and tagged, and no re-tagging occurred (December 2013, n = 8; March 2014, n = 2) (Table S1 in Supplement 1 at www.int-res.com/ articles/suppl/n040p075_supp/). While some individuals were detected outside their respective bays, no individual captured in Manglar Bay was ever detected within Tortuga Bay and vice versa for turtles captured from Tortuga Bay. Individual turtle size at tagging $(\mathrm{n}=$ 36) ranged from 38 to $70 \mathrm{~cm}(\mathrm{SCL} ; 50.61 \pm 7.84 \mathrm{~cm})$, with no significant difference in size between the locations (Manglar Bay, $51.42 \pm 8.14 \mathrm{~cm}, \mathrm{n}=26$; Tortuga Bay, $48.5 \pm 6.93 \mathrm{~cm}, \mathrm{n}=10$ ). After removing the first $7 \mathrm{~d}$ in each detection log (due to the anticipated tagging effects), days at liberty per transmitter ranged from 25 to $600 \mathrm{~d}(167.08 \pm 148.57 \mathrm{~d})$, with a mean residency index of $0.80 \pm 0.26$. There was no significant effect of size and capture location on detection number, days detected, days at liberty, or residency index and no effect of size on network metrics (network density, $\mathrm{APL}$, and $\mathrm{Bi}^{\text {mean }}$ ) for turtles tagged in Manglar Bay. However, there was a significant effect of size $\left(F_{1,33}=7.53, \mathrm{p}=0.01\right)$ and capture location $\left(F_{1,33}=\right.$ $62.73, \mathrm{p}<0.001)$ on station count, with larger turtles and turtles from Manglar Bay having higher station counts (Table S2 in Supplement 1). There was no effect of size on number of paths, but there was a significant effect of capture location on number of paths $\left(F_{1,33}=31.26, \mathrm{p}<0.001\right)$, with the greater number of paths exhibited by Manglar Bay turtles compared with Tortuga Bay turtles, potentially an artifact of the number of receivers and thus detection coverage. 


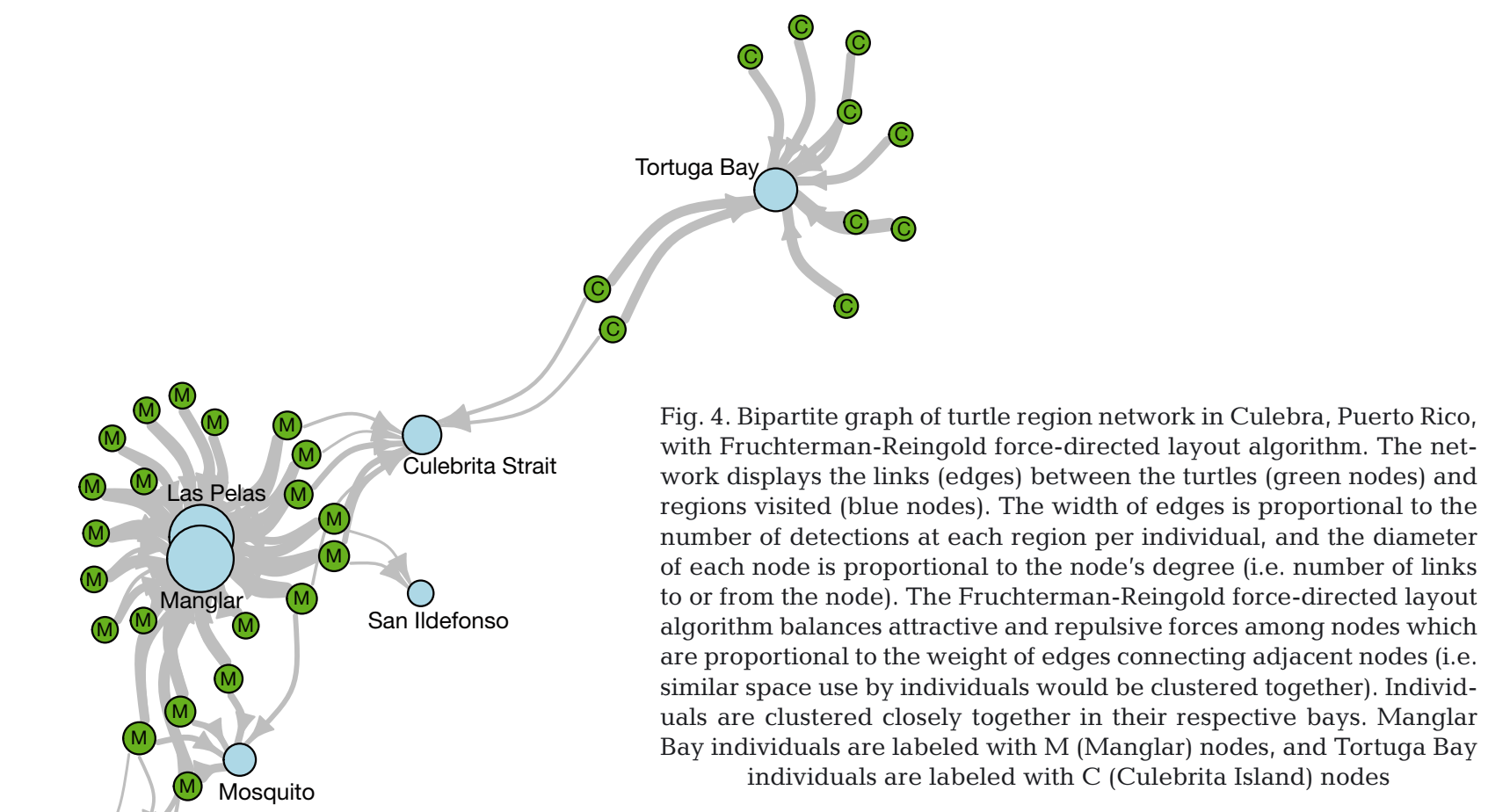

Honda

\subsection{Movements, connectivity, and space use outside, within, and across bays}

Using the Fruchterman-Reingold force-directed layout algorithm, based on attractive and repulsive forces among the nodes, the bipartite graph shows heterogeneous space use across turtles captured in Manglar Bay $(\mathrm{n}=21)$ and turtles captured in Tortuga Bay $(\mathrm{n}=10)$ (Fig. 4). Turtles remained near their capture origin, with only a few Manglar Bay individuals detected west of the bay in Mosquito, Dakity, and Honda Bay and in the east to San Ildefonso and Culebrita Strait. While turtles were never detected across capture location bays, 6 turtles captured from Manglar Bay and 2 turtles captured from Tortuga Bay were detected in Culebrita Strait, but no individual here had more than 100 detections. Moreover, turtles tagged from Tortuga Bay were never detected on any receiver farther away than Culebrita Strait.

\subsection{Community network structuring}

Network communities or modules were found within the bipartite graph by 6 different community detection algorithms. These algorithms clustered nodes (i.e. individuals and locations) into modules (groups of individuals and locations) that represent potential network communities. Four of the 6 algorithms (Fast-Greedy, Spin-Glass, Label-Propagation, and Multilevel) produced identical modules with the highest modularity score (0.197, Table 1$)$. The 4 algorithms partitioned the bipartite graph into 3 modules (Fig. 5b); 1 of the 3 modules was found to be a significant community $(p<0.001)$ which partitioned all 10

Table 1. Results from the 6 community detection algorithms applied to the bipartite graph (31 green turtles with 8 regions consisting of 48 of the 59 receivers). These algorithms cluster the nodes (i.e. individuals and locations) into modules. Modularity, ranging from 0 to 1, indicates the ability of the community detection algorithms to partition the bipartite graph. Modularity is the fraction of edges within selected modules minus the fraction that would occur if edges were randomly distributed across nodes. The higher the modularity score, the better the algorithm performed at clustering. Significant modules $(p>0.05)$ under the Wilcoxon rank-sum test indicate there are significantly more connections within a module than outside of it and thus are termed a community

\begin{tabular}{|lccc|}
\hline $\begin{array}{l}\text { Community } \\
\text { detection algorithm }\end{array}$ & Modularity & $\begin{array}{c}\text { No. of } \\
\text { modules } \\
\text { detected }\end{array}$ & $\begin{array}{c}\text { No. of } \\
\text { significant } \\
\text { modules }\end{array}$ \\
\hline Leading-Eigenvector & 0.186 & 5 & 1 \\
Fast-Greedy & 0.197 & 3 & 1 \\
Spin-Glass & 0.197 & 3 & 1 \\
Label-Propagation & 0.197 & 3 & 1 \\
Walk-Trap & 0.173 & 5 & 1 \\
Multilevel & 0.197 & 3 & 1 \\
\hline
\end{tabular}


a)

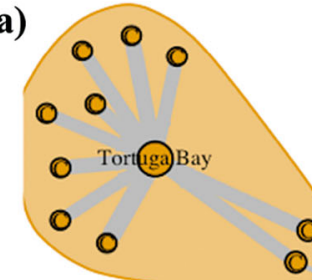

b)

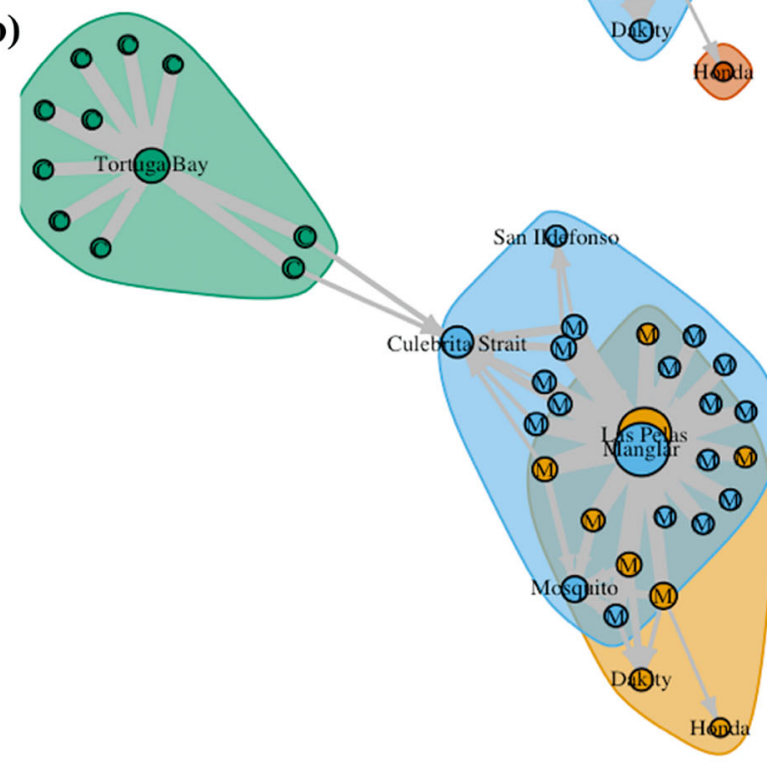

c)

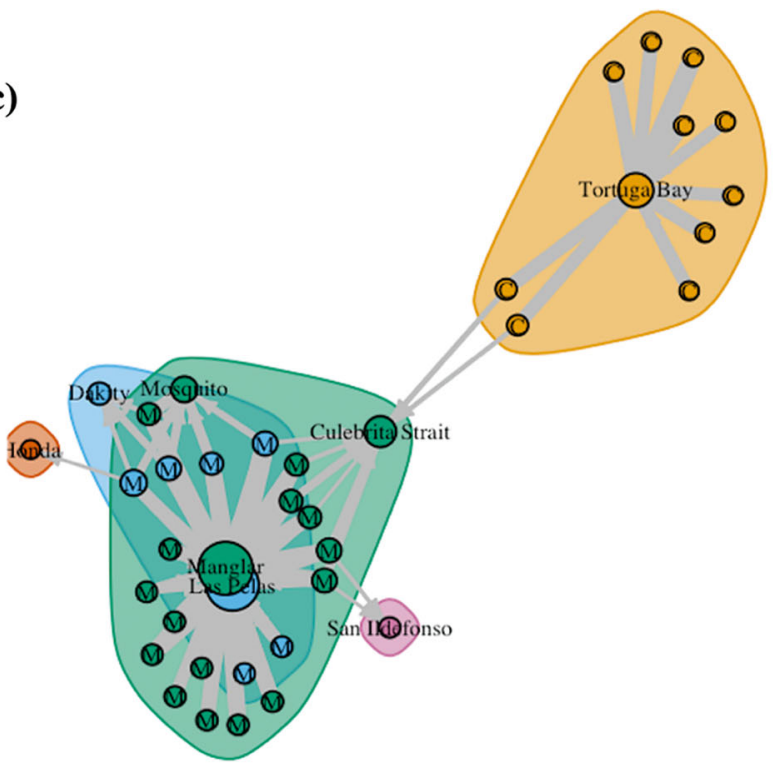

Tortuga Bay captured turtles with the Tortuga Bay node. The other 2 modules consisted of 6 Manglar Bay captured turtles partitioned with Las Pelas, Dakity, and Honda nodes $(p=0.926)$ and 15 turtles partitioned with Manglar, Mosquito, and San Ildefonso nodes $(p=0.062)$. The 2 other algorithms (LeadingEigenvector and Walk-Trap) performed worse, with modularity scores of 0.186 and 0.173 , respectively. Both found 5 similar modules (Fig. 5a,c) to each other within the bipartite graph, and both had 1 significant module, the Tortuga Bay community. There was a slight difference in placement of some Manglar Bay individuals across the modules, and both algorithms created 2 modules that only consisted of 1 node or 1 turtle. No anti-communities, i.e. significantly more connections outside the module than within it (Finn et al. 2014), were found by any detection algorithm.

\subsection{Spatio-temporal drivers within Manglar Bay}

Using the model with the best fit based on the lowest WAIC value, the final model consisted of 6 fixed covariates (lagoon [continuous], macroalgae [continuous], seagrass [continuous], diel period [categorical with 2 levels], tide height [continuous], tide daily range [continuous]) and 2 interaction terms (diel period [categorical with 2 levels] $\times$ seagrass and diel period $\times$ tide height). Green turtle presence and absence were largely explained by lagoon, macroalgae, the interaction between seagrass and diel period, and the random spatial and temporal effects (Table 2).

Juvenile green turtles were most likely to be present in areas with higher lagoon habitat values (lagoon, posterior mean $=1.22 ; 95 \% \mathrm{CI}=[0.13,2.31])$ and in areas with higher seagrass habitat values at night (diel [night]: seagrass, posterior mean $=0.29 ; 95 \% \mathrm{CI}=$ $[0.14,0.45])$. Turtles were less likely to be present in areas with higher macroalgae habitat values (macroalgae, posterior mean $=-0.56 ; 95 \% \mathrm{CI}=[-1.0,-0.10])$. The predicted and observed values (presences and absences) across hour at each station region show

Fig. 5. Bipartite graphs with identified turtle community structuring (i.e. modules) via the 6 community detection algorithms. Algorithms clustered nodes (i.e. individuals and locations) into modules (groups of individuals and locations). Modules along with their nodes are labeled with different colors. Individual turtle nodes were also labeled by the location they were captured in (M: Manglar; C: Culebrita). FastGreedy, Spin-Glass, Label-Propagation, and Multilevel had identical modules generated. (a) Leading-Eigenvector; (b) Fast-Greedy, Spin-Glass, Label-Propagation, and Multilevel; and (c) Walk-Trap algorithms 

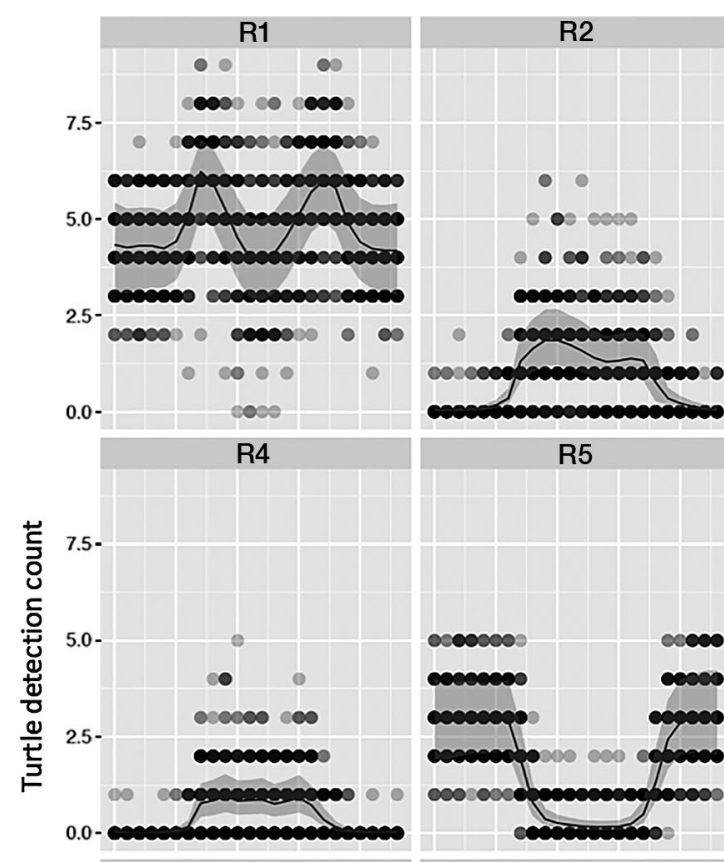

R5
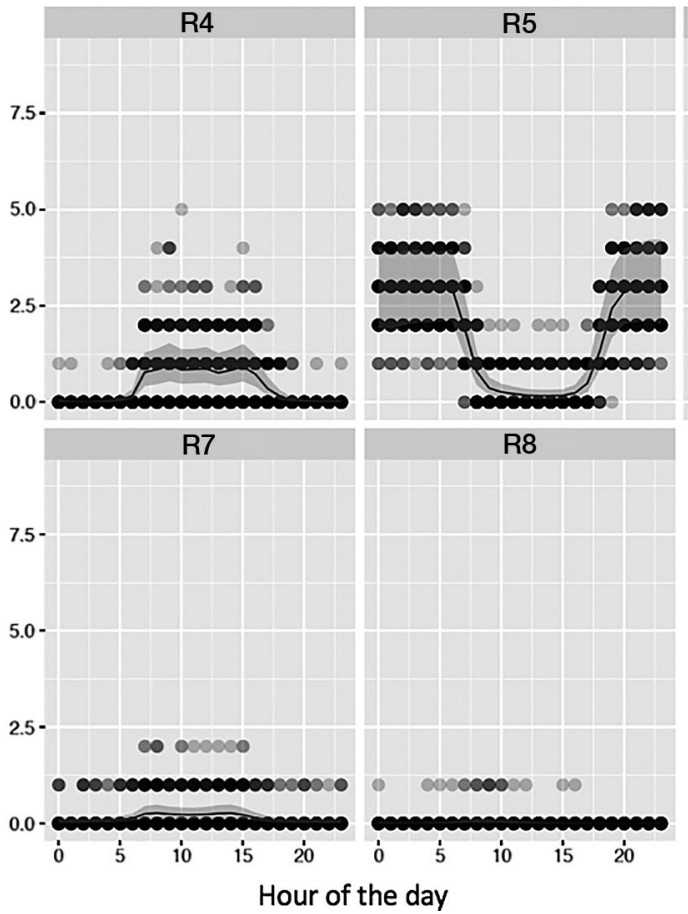

Fig. 6. Observed vs. fitted values (presences and absences) broken down by region (labeled R1-R8) at the hour level for the Bayesian presence-absence binomial model of 9 turtles within Manglar Bay across $60 \mathrm{~d}$. Dots show the observed number of turtles (0-9) for each hour, and black line with gray credible interval shows the expected value for the number of turtles from the best model

heterogeneous space use across time (Fig. 6). While space use was variable across individual turtles (Fig. S1 in Supplement 1), turtles largely followed a general spatiotemporal pattern within Manglar Bay. Turtles were most likely to be detected in the back portion of Manglar Bay (Region 1, R1 in Fig. 3) across all hours, with the highest probabilities between 07:00 and 17:00 $\mathrm{h}$. In addition, in the back portion of Manglar Bay, turtles were most likely to be detected in the western portion of Manglar Bay (Regions 5 and 6, Fig. 3) at night, between 19:00 and 06:00 h. Turtles were more likely to be detected in the eastern portion of Manglar Bay (Regions 2, 3, and 4, Fig. 3) during daylight (between 08:00 and 17:00 h). Turtles were
R3 000

$\infty 0$

coscecono

coseccocese

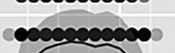

R6

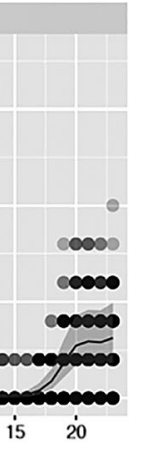

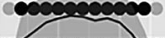

rarely detected in the furthest western region (Region 8, Fig. 3); however, if they were detected here, it occurred most often during daytime hours.

The final model correctly categorized $88 \%$ of the presences as determined by the confusion matrix (i.e. a classification table that compares actual and predicted presences and absences to one another), and the dispersion statistic derived via sum of squared Pearson residuals was 0.82 , slightly underdispersed. Simulating from the posterior distributions of the regression parameters a thousand times, we observed an overestimation of zeros and an overestimation of nines (Fig. S2 in Supplement 1). The simulation in combination with the dispersion statistic highlighted the potential misinterpretation of the variance structure. While computationally intense and difficult to implement, this model may have benefitted by using a zero inflated binomial distribution (due to many absences) rather than a binomial distribution. While some autocorrelation still existed, it was largely corrected for with the SPDE approach and the hourly station temporal dependency structure (Figs. S3 \& S4 in Supplement 1).

Predicted probability distribution maps of green turtles were generated for each hour across Manglar Bay, with tide height and tidal range being held constant at their means and using the

Table 2. Results from final Bayesian presence and absence binomial model of 9 green turtles within Manglar Bay across $60 \mathrm{~d}$. Six covariates along with 2 interaction terms were included in the model. In addition, the model was fit with a spatial dependency structure to account for spatial autocorrelation (via the stochastic partial differential equation) and 3 random walk smoothers to account for temporal autocorrelation (tide height, hour of the day, and study day) $\mathrm{Q}_{0.025}$ and $Q_{0.975}$ represent the $95 \%$ credible intervals of the parameter estimates

\begin{tabular}{|lrccr|}
\hline Predictor & Mean & SD & $\mathrm{Q}_{0.025}$ & $\mathrm{Q}_{0.975}$ \\
\hline Intercept & -3.91 & 1.02 & -5.91 & -1.91 \\
lagoon & 1.22 & 0.56 & 0.13 & 2.31 \\
macroalgae & -0.56 & 0.24 & -1.0 & -0.10 \\
seagrass & 0.41 & 0.29 & -0.16 & 0.96 \\
diel (night) & -0.29 & 0.09 & -0.47 & -0.12 \\
tide height & -0.17 & 0.36 & -0.87 & 0.53 \\
tide range & 0.05 & 0.07 & -0.08 & 0.19 \\
diel (night):seagrass & 0.29 & 0.08 & 0.14 & 0.45 \\
diel (night):tide height & -0.05 & 0.03 & -0.10 & 0.00 \\
\hline
\end{tabular}




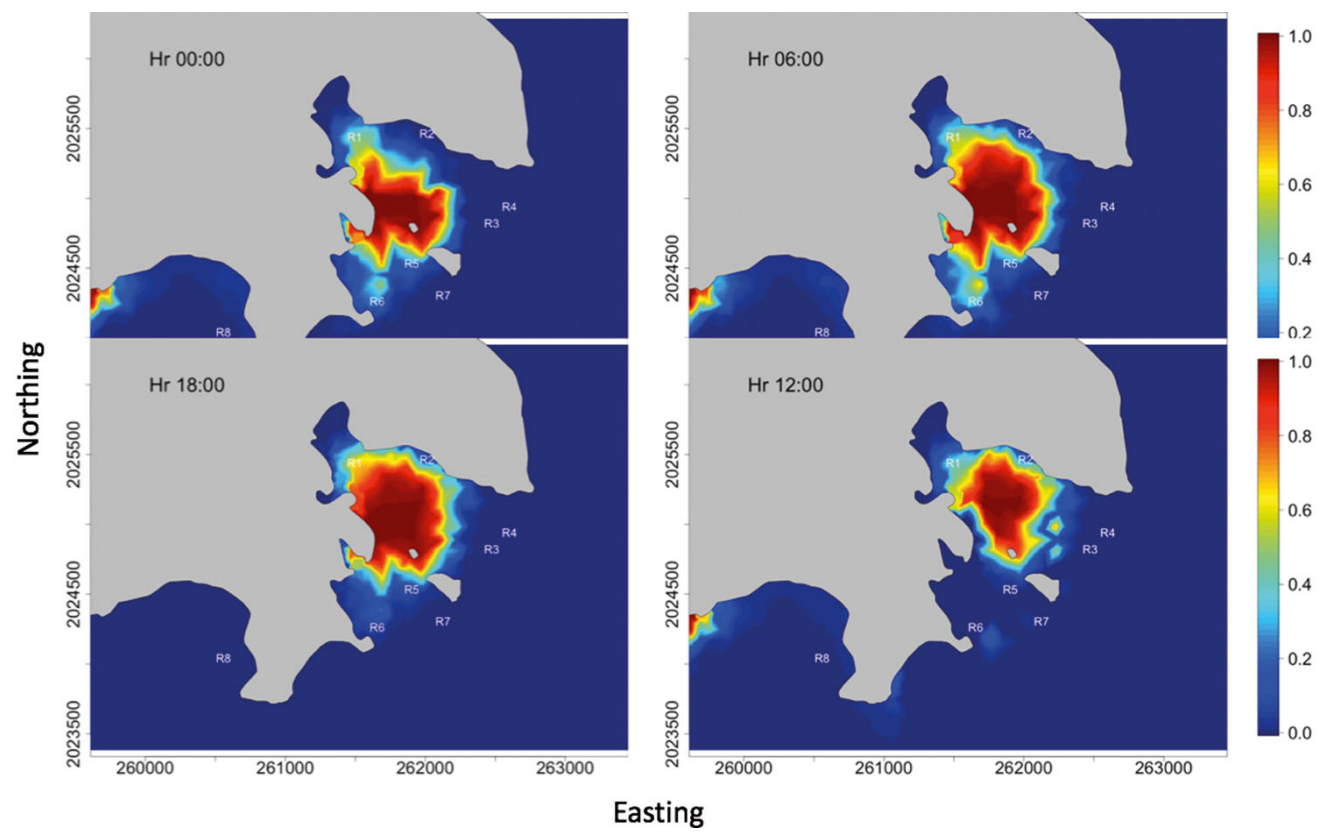

Fig. 7. Using the final Bayesian presence-absence binomial model parameter estimates, the spatio-temporal probability distribution of turtles within and around Manglar Bay at the hour level (0:00, 06:00, 12:00, and 18:00 h shown) was produced, with 0 (dark blue) indicating $0 \%$ probability of turtle presence and 1 (red) indicating $100 \%$ probability of turtle presence. We derived 2155 habitat point estimates from our original mesh (2155 vertices); from each habitat kernel density estimate, these point estimates were used to predict turtle distribution across Manglar Bay. Spatially explicit delineations for each station region were used, and predictions were set to the mean tide height and tidal range and the median study day (296). Each hour was also classified for each hourly predictive model as either day or night

median study day (296) (Fig. 7, and see the animation in Supplement 2 at www.int-res.com/articles/ suppl/n040p075_supp/). The spatial maps were consistent with the model predictions, as higher and lower presences followed patterns similar to the predicted and observed values (presences and absences) across each hour and each station region (Fig. 6). Based on habitat features, turtle presence was estimated to be low in unobserved areas such as the reef but high in unobserved areas where seagrass and lagoon habitats existed. Further, diel period appears to be linked with spatial predictions; specifically, turtle probability distributions were condensed within the central and western portion of Manglar Bay at night and more dispersed towards the eastern portion of Manglar Bay during the day. Our model indicated turtles had the highest probabilities of detection in the back portion of Manglar Bay, also known as Region 1. Further, these probabilities in Region 1 were the highest between 07:00 and 17:00 h. However, our predictive probability distribution maps (which account for habitat within the entire bay) showed the highest presences to be in the central part of the lagoon, in areas that were considered unobservable with our receivers.

\section{DISCUSSION}

The main aims of this study were to examine movement patterns and connectivity of immature turtles within, outside, and across Manglar Bay on Culebra Island and Tortuga Bay on Culebrita Island, Puerto Rico, as well as to determine the spatio-temporal drivers of presence and absence within Manglar Bay. As suggested by Patrício et al. (2011), juvenile green turtles around Culebra exhibit high site fidelity to specific bays, with larger turtles leaving on brief trips. Further, the size distribution of tagged turtles in this study was similar to that reported by Patrício et al. (2014) and thus likely was representative of individuals that were not tagged. There was little overlap of space use outside respective bays for turtles captured in either Manglar or Tortuga Bay; further, no turtle was ever detected entering the opposing bay.

Our model incorporating habitat kernel densities indicated that turtles were more likely to be present in areas of lagoon habitat and seagrass at night and less likely to be in macroalgae habitat. We used parameter estimates from the model to predict space use of 9 turtles across Manglar Bay; our hourly probability distributions proved to be accurate and demonstrated turtles moving in predictive 
patterns across the bay. Here, acoustic telemetry in combination with novel analytical methods provides unique insights on their movement patterns such as space use and connectivity and their spatio-temporal drivers. These methods included network analysis, community detection algorithms, and presenceabsence Bayesian modeling while accounting for autocorrelation.

Within an ideal free distribution framework (Fretwell \& Lucas 1969), individual animals should arrange themselves across space, based on food supply, in a way that no individual has a greater advantage than another; thus, input matching is achieved via bottomup processes (Milinski \& Parker 1991). However, through top-down processes, predation risk often heavily alters spatial distributions and ultimately impacts lifetime reproductive success based on the trade-off between energetic input and predation risk (Lima \& Dill 1990, Moody et al. 1996). We suspect top-down processes related to predation risk occur within Culebra considering immature green turtles had differential space use, as indicated by network analysis, and never moved between Manglar Bay and Tortuga Bay, the 2 highest turtle density bays on Culebra that are only separated by $2 \mathrm{~km}$. While anecdotal evidence suggests limited predator burdens (e.g. tiger sharks) around Culebra, predation risk and its non-lethal effects (trait-mediated or risk effects) are likely a major selective force in the evolution of behaviors which still drive spatial distributions of immature turtles around Culebra.

Furthermore, while genetic sampling suggested the recruitment origins for juvenile green turtles were similar across the 2 bays in Culebra (Patrício et al. 2017), somatic growth was significantly greater in Manglar Bay than in Tortuga Bay, with minimum ages at maturity of 14 and $22 \mathrm{yr}$, respectively (Patrício et al. 2014). Since no differential recruitment (Patrício et al. 2017) or movement across bays exists, habitat quality and availability (Bjorndal et al. 2000) in combination with predation risk (innate or learned) are likely driving these different rates of somatic growth. Manglar Bay is comprised of macroalgae and the seagrass Thalassia testudinum, the primary diet of green turtles in the Greater Caribbean (Bjorndal 1980), while Tortuga Bay is predominantly covered by seagrasses Syringodium filiforme and Halodule wrightii. Residency was high (0.80) for turtles regardless of size or location, supporting previous findings (Mendonca 1983, Brill et al. 1995, Makowski et al. 2006, Colman et al. 2015) that immature green turtles inhabit smaller but well-defined areas when ecological resources (i.e. food and shelter) are tightly clustered. The compressed bipartite graphs and community plots show turtles in Culebra use welldefined areas. However, there was an effect of turtle size and capture location on station count; movement data showed larger individuals were more likely to exit the bay for brief trips, which is consistent across other study areas (Seminoff et al. 2003, Koch et al. 2007, Bresette et al. 2010). Potentially, as suggested by our data, predation risk and exploratory behaviors decrease and increase with size, respectively.

\subsection{Spatio-temporal drivers within Manglar Bay}

Our results suggest turtles favored lagoon habitat followed by seagrass habitat at night. Overall, turtles were much less likely to be present in macroalgae habitat. Based on the predicted hourly probability distribution maps, turtle presence shifted from the central and western portions of Manglar Bay at night towards the eastern portion during the day. We anticipated turtles would be detected exiting and entering Manglar Bay for shelter and potentially safer habitats during the night via the large channel in Region 4; however, we saw the 9 selected turtles largely remained within the lagoon during the night. Although reef structure exists around Culebra and generally serves as resting habitat for turtles to reduce predation risk (Ogden et al. 1983, Makowski et al. 2006, Taquet et al. 2006, Hazel et al. 2009), some turtles within Culebra may find shelter in the protected lagoon as they would in an exposed patch reef system. In agreement with our findings, Blumenthal et al. (2010) also reported some green turtles remaining within lagoon habitats at night. Further, turtles may be selecting seagrass at night for foraging opportunities if light conditions are suitable (Taquet et al. 2006).

\subsection{Conclusions}

Seagrass communities, the main diet of green sea turtles, are considered threatened globally (Waycott et al. 2009) and are highly vulnerable to human disturbances including urban and agriculture runoff, coastal development, and dredging (Grech et al. 2012). Since Culebra Island, Puerto Rico, is classified as Resource Category I critical habitat for the green turtle (63 FR 46693, September 2, 1998) and largely protected through the Culebra National Wildlife Reserve, its coastal habitats are still relatively undisturbed, providing an excellent window into natural 
processes. While habitats within Culebra are still largely intact, multiple embayments are becoming increasingly threatened by sewage wastewater contamination and/or coastal development (e.g. mangrove clearing, high sediment loads). Further, plans for dredging for marinas are being proposed in these sensitive seagrass habitats. Considering turtles in Culebra exhibit high fidelity within the bays, it is imperative to protect these distinct habitats that serve as both shelter and foraging areas. This is especially pertinent since the survival of immature turtles in Culebra could positively affect Caribbean-wide nesting populations, specifically those of Costa Rica, Mexico, east-central Florida, and Suriname (Patrício et al. 2017). The protection of these essential juvenile turtle developmental habitats ensures continued recruitment into recovering green turtle populations.

Acknowledgements. Part of the research support was provided by the Department of Natural and Environmental Resources of Puerto Rico (DNER), US National Marine Fisheries Service (NMFS-NOAA, Section 6, grant nos. NA 4720436 and NA 4720048). Work was conducted under permits from NMFS-NOAA (permit nos. 14949, 1518-01, and 19697) and PR-DRNA (permit no. 2016-EPE-003). This research was also supported by the Allen Family Foundation and the University of Puerto Rico Sea Grant Program awarded to A.J.D. and J.T.F. Thanks to Curt Griffin, Jacob Brownscombe, Tyler Gagne, Sarah Becker, Chris Haak, Megan Waidlich, Dr. Craig Lilyestrom (DNER), Ricardo Colón-Merced and Ana Roman (Culebra National Wildlife Refuges, US Fish and Wildlife Service), Rolando Soler, Misael Feliciando, Nilda Jimenez, Jonathan Lopez, Julio Vargas, Todd and Shellie Plaia, Walter and Monica Reider, Sammy Hernandez, and Zorida Mendez for their contributions and assistance in the field and/or logistical support. Finally, we thank the handling editor and the 3 anonymous reviewers for their excellent feedback and suggestions.

\section{LITERATURE CITED}

Bakka H, Rue H, Fuglstad GA, Riebler A and others (2018) Spatial modeling with R INLA: a review. Wiley Interdiscip Rev Comput Stat 10:e1443

Bivand R, Lewin-Koh N (2013) maptools: Tools for reading and handling spatial objects. R package version 08-27. https:// CRAN.r-project.org/package=maptools

Bjorndal KA (1980) Nutrition and grazing behavior of the green turtle Chelonia mydas. Mar Biol 56:147-154

Bjorndal KA (1997) Foraging ecology and nutrition of sea turtles. In: Lutz PL, Musick JA (eds) The biology of sea turtles, Vol 1. CRC Press, Boca Raton, FL, p 199-231

Bjorndal KA, Bolten AB, Chaloupka MY (2000) Green turtle somatic growth model: evidence for density dependence. Ecol Appl 10:269-282

Blangiardo M, Cameletti M (2015) Spatial and spatio-temporal Bayesian models with R-INLA. John Wiley \& Sons, Chichester

Blondel VD, Guillaume JL, Lambiotte R, Lefebvre E (2008) Fast unfolding of communities in large networks. J Stat Mech 2008:P10008
Blumenthal JM, Austin TJ, Bothwell JB, Broderick AC and others (2010) Life in (and out of) the lagoon: fine-scale movements of green turtles tracked using time-depth recorders. Aquat Biol 9:113-121

Bolten AB (2003) Variation in sea turtle life history patterns: neritic vs. oceanic developmental stages. In: Lutz PL, Musick J, Wyneken J (eds) The biology of sea turtles, Vol 2. CRC Press, Boca Raton, FL, p 243-257

* Bresette MJ, Witherington BE, Herren RM, Bagley DA and others (2010) Size-class partitioning and herding in a foraging group of green turtles Chelonia mydas. Endang Species Res 9:105-116

Brill RW, Balazs GH, Holland KN, Chang RKC, Sullivan S, George JC (1995) Daily movements, habitat use, and submergence intervals of normal and tumor-bearing juvenile green turtles (Chelonia mydas L.) within a foraging area in the Hawaiian islands. J Exp Mar Biol Ecol 185:203-218

Brooks LB, Harvey JT, Nichols WJ (2009) Tidal movements of East Pacific green turtle Chelonia mydas at a foraging area in Baja California Sur, México. Mar Ecol Prog Ser 386:263-274

* Brownscombe JW, Griffin LP, Gagne TO, Haak CR, Cooke SJ, Finn JT, Danylchuk AJ (2019) Environmental drivers of habitat use by a marine fish on a heterogeneous and dynamic reef flat. Mar Biol 166:18

Collazo JA, Boulon R Jr, Tallevast TL (1992) Abundance and growth patterns of Chelonia mydas in Culebra, Puerto Rico. J Herpetol 26:293-300

* Colman LP, Patrício ARC, McGowan A, Santos AJB, Marcovaldi MÂ, Bellini C, Godley BJ (2015) Long-term growth and survival dynamics of green turtles (Chelonia mydas) at an isolated tropical archipelago in Brazil. Mar Biol 162: 111-122

Congdon JD, Dunham AE (1997) Contributions of long-term life history studies to conservation biology. In: Meffe GK, Carroll CR (eds) Principles of conservation biology, 2nd edn. Sinauer Associates, Sunderland, MA, p 205-206

Csardi G, Nepusz T (2006) The igraph software package for complex network research. InterJ Complex Syst 1695:1-9

Dale MRT, Fortin MJ (2010) From graphs to spatial graphs. Annu Rev Ecol Evol Syst 41:21-38

Diez CE, van Dam RP, Velez-Zuazo X, Torres F, Scharer M, Molina M (2010) Habitat and population assessment of Caribbean green turtle aggregations inhabiting the Culebra Archipelago's coastal waters. In: Dean K, LópezCastro MC (eds) Proc 28th Annu Symp Sea Turtle Biol Conserv. NOAA Tech Memo NMFS-SEFSC, p 130-131

Finn JT, Brownscombe JW, Haak CR, Cooke SJ, Cormier R, Gagne T, Danylchuk AJ (2014) Applying network methods to acoustic telemetry data: modeling the movements of tropical marine fishes. Ecol Modell 293:139-149

* Fleming CH, Fagan WF, Mueller T, Olson KA, Leimgruber P, Calabrese JM (2015) Rigorous home range estimation with movement data: a new autocorrelated kernel density estimator. Ecology 96:1182-1188

Fortuna MA, Albaladejo RG, Fernández L, Aparicio A, Bascompte J (2009) Networks of spatial genetic variation across species. Proc Natl Acad Sci USA 106:19044-19049

Fretwell SD, Lucas HL Jr (1969) On territorial behavior and other factors influencing habitat distribution in birds. I. Theoretical development. Acta Biotheor 19:16-36

*Fruchterman TMJ, Reingold EM (1991) Graph drawing by force directed placement. Softw Pract Exper 21: 1129-1164 
Grech A, Chartrand-Miller K, Erftemeijer P, Fonseca M and others (2012) A comparison of threats, vulnerabilities and management approaches in global seagrass bioregions. Environ Res Lett 7:024006

*Hamann M, Godfrey MH, Seminoff JA, Arthur K and others (2010) Global research priorities for sea turtles: informing management and conservation in the 21st century. Endang Species Res 11:245-269

*Hazel J, Lawler IR, Hamann M (2009) Diving at the shallow end: green turtle behaviour in near-shore foraging habitat. J Exp Mar Biol Ecol 371:84-92

Heppell SS (1998) Application of life-history theory and population model analysis to turtle conservation. Copeia 367-375

Heppell SS, Caswell H, Crowder LB (2000) Life histories and elasticity patterns: perturbation analysis for species with minimal demographic data. Ecology 81:654-665

Heppell SS, Snover ML, Crowder LB (2002) Sea turtle population ecology. In: Lutz PL, Musick JA, Wyneken J (eds) The biology of sea turtles, Vol 2. CRC Press, Boca Raton, FL, p 275-306

* Heupel MR, Munroe SEM, Lédée EJI, Chin A, Simpfendorfer CA (2019) Interspecific interactions, movement patterns and habitat use in a diverse coastal shark assemblage. Mar Biol 166:68

Jacoby DMP, Freeman R (2016) Emerging network-based tools in movement ecology. Trends Ecol Evol 31:301-314

Jacoby DMP, Brooks EJ, Croft DP, Sims DW (2012) Developing a deeper understanding of animal movements and spatial dynamics through novel application of network analyses. Methods Ecol Evol 3:574-583

Johnson DS, Hooten MB, Kuhn CE (2013) Estimating animal resource selection from telemetry data using point process models. J Anim Ecol 82:1155-1164

Jones TT, Seminoff JA (2013) Feeding biology: advances from field-based observations, physiological studies, and molecular techniques. In: Wyneken J, Lohmann KJ, Musick JA (eds) The biology of sea turtles, Vol 3. CRC Press, Boca Raton, FL, p 211-247

Kessel ST, Hussey NE, Webber DM, Gruber SH, Young JM, Smale MJ, Fisk AT (2015) Close proximity detection interference with acoustic telemetry: the importance of considering tag power output in low ambient noise environments. Anim Biotelem 3:5

Koch V, Brooks LB, Nichols WJ (2007) Population ecology of the green/black turtle (Chelonia mydas) in Bahia Magdalena, Mexico. Mar Biol 153:35-46

Kurvers RHJM, Krause J, Croft DP, Wilson ADM, Wolf M (2014) The evolutionary and ecological consequences of animal social networks: emerging issues. Trends Ecol Evol 29:326-335

Lamont MM, Putman NF, Fujisaki I, Hart KM (2015) Spatial requirements of different life-stages of the loggerhead turtle (Caretta caretta) from a distinct population segment in the northern Gulf of Mexico. Herpetol Conserv Biol 10:26-43

Lédée EJI (2015) Improving understanding of spatial ecology through network analysis of acoustic monitoring data. PhD dissertation, James Cook University, Queensland

兰édée EJI, Heupel MR, Tobin AJ, Knip DM, Simpfendorfer CA (2015) A comparison between traditional kernelbased methods and network analysis: an example from two nearshore shark species. Anim Behav 103:17-28

Liaw A, Wiener M (2002) Classification and regression by
randomForest. R News 2:18-22

*Lima SL, Dill LM (1990) Behavioral decisions made under the risk of predation: a review and prospectus. Can J Zool 68:619-640

* Lindgren F, Rue H, Lindström J (2011) An explicit link between Gaussian fields and Gaussian Markov random fields: the stochastic partial differential equation approach. J R Stat Soc Series B Stat Methodol 73:423-498

Makowski C, Seminoff JA, Salmon M (2006) Home range and habitat use of juvenile Atlantic green turtles (Chelonia mydas L.) on shallow reef habitats in Palm Beach, Florida, USA. Mar Biol 148:1167-1179

*Mendonca MT (1983) Movements and feeding ecology of immature green turtles (Chelonia mydas) in a Florida lagoon. Copeia 1013-1023

Milinski M, Parker GA (1991) Competition for resources. In: Krebs JR, Davies NB (eds) Behavioral ecology: an evolutionary approach, 3rd edn. Blackwell, Oxford, p 137-168

Moody AL, Houston AI, McNamara JM (1996) Ideal free distributions under predation risk. Behav Ecol Sociobiol 38: 131-143

* Muñoz F, Pennino MG, Conesa D, López-Quílez A, Bellido JM (2013) Estimation and prediction of the spatial occurrence of fish species using Bayesian latent Gaussian models. Stochastic Environ Res Risk Assess 27: 1171-1180

Newman ME (2006) Modularity and community structure in networks. Proc Natl Acad Sci USA 103:8577-8582

*Newman MEJ, Girvan M (2004) Finding and evaluating community structure in networks. Phys Rev E Stat Nonlin Soft Matter Phys 69:026113

\% Ogden JC, Robinson L, Whitlock K, Daganhardt H, Cebula R (1983) Diel foraging patterns in juvenile green turtles (Chelonia mydas L.) in St. Croix United States Virgin Islands. J Exp Mar Biol Ecol 66:199-205

* Parker DM, Dutton PH, Balazs GH (2011) Oceanic diet and distribution of haplotypes for the green turtle, Chelonia mydas, in the central North Pacific. Pac Sci 65:419-432

*Patrício AR, Velez-Zuazo X, Diez CE, Dam RV, Sabat AM (2011) Survival probability of immature green turtles in two foraging grounds at Culebra, Puerto Rico. Mar Ecol Prog Ser 440:217-227

* Patrício R, Diez CE, van Dam RP (2014) Spatial and temporal variability of immature green turtle abundance and somatic growth in Puerto Rico. Endang Species Res 23: $51-62$

* Patrício AR, Diez CE, van Dam RP, Godley BJ (2016) Novel insights into the dynamics of green turtle fibropapillomatosis. Mar Ecol Prog Ser 547:247-255

Patrício AR, Vélez-Zuazo X, van Dam RP, Diez CE (2017) Genetic composition and origin of juvenile green turtles foraging at Culebra, Puerto Rico, as revealed by mtDNA. Lat Am J Aquat Res 45:506-520

* Pons P, Latapy M (2006) Computing communities in large networks using random walks. J Graph Algorithms Appl 10:191-218

R Core Team (2018) R: a language and environment for statistical computing. R Foundation for Statistical Computing, Vienna. www.R-project.org

* Raghavan UN, Albert R, Kumara S (2007) Near linear time algorithm to detect community structures in large-scale networks. Phys Rev E Stat Nonlin Soft Matter Phys 76: 036106

Reichardt J, Bornholdt S (2006) Statistical mechanics of community detection. Phys Rev E Stat Nonlin Soft Matter 
Phys 74:016110

Reubens JT, Pasotti F, Degraer S, Vincx M (2013) Residency, site fidelity and habitat use of Atlantic cod (Gadus morhua) at an offshore wind farm using acoustic telemetry. Mar Environ Res 90:128-135

Rue H, Martino S, Lindgren F, Simpson D, Riebler A, Krainski ET (2009) INLA: functions which allow to perform a full Bayesian analysis of structured additive models using integrated nested Laplace approximation. www.RINLA.org

Seminoff JA, Resendiz A, Nichols WJ (2002) Home range of green turtles Chelonia mydas at a coastal foraging area in the Gulf of California, Mexico. Mar Ecol Prog Ser 242: 253-265

Seminoff JA, Jones TT, Resendiz A, Nichols WJ, Chaloupka MY (2003) Monitoring green turtles (Chelonia mydas) at a coastal foraging area in Baja California, Mexico: multiple indices to describe population status. J Mar Biol Assoc UK 83:1355-1362

Sheather SJ, Jones MC (1991) A reliable data-based bandwidth selection method for kernel density estimation. J R Stat Soc B 53:683-690

Song J, Singh M (2013) From hub proteins to hub modules: the relationship between essentiality and centrality in the yeast interactome at different scales of organization. PLOS Comput Biol 9:e1002910

Tamassia R (2013) Handbook of graph drawing and visualization. CRC Press, Boca Raton, FL

Taquet C, Taquet M, Dempster T, Soria M, Ciccione S, Roos D, Dagorn L (2006) Foraging of the green sea turtle Chelonia mydas on seagrass beds at Mayotte Island (Indian Ocean), determined by acoustic transmitters. Mar Ecol Prog Ser 306:295-302

Editorial responsibility: Sandra Hochscheid, Naples, Italy
Urban D, Keitt T (2001) Landscape connectivity: a graph theoretic perspective. Ecology 82:1205-1218

Velez-Zuazo X, Diez CE, van Dam RP, Torres-Velez F (2010) Genetic structure and origin of a juvenile aggregation affected by fibropapillomatosis: potential impact on adult recruitment. In: Dean K, López-Castro MC (eds) Proc 28th Annu Symp Sea Turtle Biol Conserv. NOAA Tech Memo NMFS-SEFSC, p 156

*Wallace BP, Lewison RL, McDonald SL, McDonald RK and others (2010) Global patterns of marine turtle bycatch. Conserv Lett 3:131-142

Watanabe S (2010) Asymptotic equivalence of Bayes cross validation and widely applicable information criterion in singular learning theory. J Mach Learn Res 11: 3571-3594

Waycott M, Duarte CM, Carruthers TJ, Orth RJ and others (2009) Accelerating loss of seagrasses across the globe threatens coastal ecosystems. Proc Natl Acad Sci USA 106:12377-12381

*Whiting SD, Miller JD (1998) Short term foraging ranges of adult green turtles (Chelonia mydas). J Herpetol 32: 330-337

Winton MV, Fay G, Haas HL, Arendt M and others (2018) Estimating the distribution and relative density of satellite-tagged loggerhead sea turtles using geostatistical mixed effects models. Mar Ecol Prog Ser 586:217-32

Zuur A, Ieno EN, Walker N, Saveliev AA, Smith GM (2009) Mixed effects models and extensions in ecology with R. Springer, New York, NY

Zuur AF, Ieno EN, Saveliev AA (2017) Beginner's guide to spatial, temporal, and spatial-temporal ecological data analysis with R-INLA. Vol I: using GLM and GLMM. Highland Statistics, Newburgh

Submitted: February 11, 2019; Accepted: July 19, 2019 Proofs received from author(s): September 28, 2019 